\title{
GRADIENTES DE DOPING E DEFINIÇÕES DE FRONTEIRAS: DESA- FIOS E CONTINGÊNCIAS NO ESPORTE DE ALTO RENDIMENTO
}

\author{
George Saliba Manske \\ Universidade do Vale do Itajaí, Itajaí, Santa Catarina, Brasil
}

\begin{abstract}
Resumo
Tendo em vista as condições contemporâneas de alteração das capacidades humanas no campo esportivo, este texto tem como objetivo discutir os limites e contingências envolvidas na definição e regulação do doping no esporte de alto rendimento. Articulando discussões acerca das possibilidades de otimização do desempenho físico-desportivo e dos registros provenientes da Agência Mundial Antidoping, estabelece-se uma discussão sobre os limiares de doping e as dificuldades impostas por tais condições na condução de seus processos regulatórios. Considera-se que há a necessidade de um debate amplo e revisional das políticas de doping contemporâneas, assim como, uma atenção permanente aos processos de transformações das capacidades humanas no tocante aos esportes de alto rendimento.
\end{abstract}

Palavras-chave: Esportes. Doping nos esportes. Desempenho atlético. Substâncias para melhoria do desempenho.

\section{Introdução}

A tão propalada busca da homeostase, do equilíbrio e do completo bem-estar da condição humana parece não fazer mais sentido em alguns setores da cultura nos dias atuais. Urge, na atualidade, de modo geral, enquanto preceitos, mas para grupos específicos enquanto imperativo, a necessidade não apenas de nos precavermos de qualquer condição que possa afetar nosso equilíbrio físico, mental e social, mas de nos melhorarmos, potencializarmos nossas capacidades, de estarmos sempre além de nós mesmos. Dito a partir de Ribeiro (2003), é possível inferir que caso não tenhamos declaradamente algum desconforto, desequilíbrio, doença, ou algo a ser eliminado, ou suprimido, deve haver, sem dúvida, alguma coisa a ser melhorada, potencializada, incrementada, adicionada. Não há mais espaços somente para a precaução e prevenção de desordens, é necessário, enquanto um novo dispositivo de subjetividade, otimizar as capacidades humanas. Desse modo, os investimentos no humano não estão tanto na ordem da 'anulação do mal', mas também, e, principalmente, na 'potencialização do bem', na valorização 'do mais'.

Cabe destacar que tais inferências somente são possíveis de serem ditas e escritas a partir de um modo de pensar e ações que tomaram força e proporção a partir de meados do século XX (FOUCAULT, 2010; GAUDENZI; ORTEGA, 2012; ROSE, 2013). Isto não significa necessariamente que ao longo da história os indivíduos não tenham incrementado suas capacidades, de fato, o ser humano faz isso desde muito tempo. Indica, sim, que a partir de determinado momento histórico (meados do século passado) os modos de vida do homem, incluindo sua existência, foram apropriados pelos saberes, técnicas, intervenções, aparatos e linguagem de ordem biomédica, de modo que cada vez mais a apropriação da vida - e da saúde - tem sido alvo de investimentos e saberes biomédicos e biotecnológicos. A esse fenômeno 
uma série de autores se refere como medicalização (FOUCAULT, 2010; GAUDENZI; ORTEGA, 2012; POLI NETO; CAPONI, 2007; ROSE, 2013).

Os processos de medicalização social que incidem sobre indivíduos e sociedade podem ser realizados de diversas maneiras e, dentre essas, cabe aqui aludir àqueles referentes ao uso de medicamentos. Tal recorte de discussão acerca dos medicamentos e tecnologias medicamentosas, enquanto processos e métodos medicalizantes dos corpos e da vida, serve como base para construir uma teia de argumentação acerca do doping no esporte de alto rendimento, na medida em que o doping tradicionalmente tem sido julgado sobre uma perspectiva mais medicamentosa ${ }^{1}$.

Desse modo, é possível inferir que o plano de investimentos de medicamentos ou drogas no esporte parece ser contemporâneo ao da sociedade de modo geral, na medida em que o uso ou aplicação de determinadas drogas, medicamentos ou fármacos, podem migrar do lócus esportivo para o plano social, e vice-versa. Não obstante a isso, Miah (2006) destaca que a arena esportiva é um lugar privilegiado para a convergência de aplicações tecnológicas, nas quais o uso de drogas e medicamentos são apenas alguns de seus desdobramentos. Assim, os que "trabalham no campo dos esportes", destaca Rose (2013, p. 39), "ficam apreensivos quanto ao uso de tecnologias de aprimoramento - desde remédios até potencial manipulação genética - a fim de estimular artificialmente o desempenho".

Na esteira dos processos medicalizantes da vida, Rose (2013, p. 39) solicita que suponhamos que remédios destinados a tratar o mal de Alzheimer "possam estar a ponto de abrir o caminho a toda uma série de fármacos para incrementar a memória, a inteligência, a concentração e coisas semelhantes". Acerca dessas possibilidades, Couto (2001) destaca a emergente medicalização dos corpos na busca de uma vida feliz, recorrendo a inúmeros exemplos para ilustrar a medicalização não apenas da sociedade e dos indivíduos de modo geral, mas de nossos desejos, angústias, anseios, aspirações, excitações, e conclui: "a dopagem é apenas uma manifestação da cultura hiperconsumidora que acha por bem medicalizar os hábitos da vida" (COUTO, 2001, p. 52).

Portanto, as condições sociais atuais - análogas à arena do campo esportivo - estão sob a condição cada vez maior das possibilidades de incremento das potencialidades humanas pelo uso de fármacos, drogas e genéricos. No caso do esporte de alto rendimento, lidar com esses diferentes recursos de aprimoramento na performance esportiva regulando-os, classificando-os e permitindo o uso de uns e não de outros é tarefa da Agência Mundial Antidoping (WADA-AMA).

Frente ao exposto acerca das possibilidades de incremento do rendimento humano e esportivo, e tomando as definições e ações da WADA-AMA no controle do doping no esporte é que as reflexões e os questionamentos seguintes foram organizados.

\section{Limiares de doping}

Para a Organização Mundial Antidoping, o doping é definido "como a ocorrência de uma ou mais violações do regulamento antidoping" (WADA-AMA, 2009, p. 18). Esse regulamento, descrito detalhadamente no Código Mundial Antidoping, foi adotado inicialmente no ano de 2003 e implantado efetivamente em nível mundial no ano seguinte. Porém, os elemen-

\footnotetext{
${ }^{1}$ Quanto a perspectiva hegemônica de compreensão e definição do doping é possível indicar, sumariamente, que existem substâncias e métodos proibidos que são considerados doping. No que se referem às substâncias proibidas, elas são divididas em nove categorias, a saber, estimulantes, narcóticos, canabinóides, anabólicos, hormônios, beta-agonistas, antiestrogênicos, agentes mascaradores e glicocorticóides. Além dessas substâncias, também são elencados métodos proibidos, tais como: transferência de oxigênio (doping sanguíneo); manipulação farmacológica, química e física; e, por fim, o doping genético (SANDOVAL, 2005; FEDER et al., 2000).
} 
tos que circundam o doping não podem ser referidos somente àquele ano, pois tais discussões permearam o esporte moderno de alto rendimento ao longo do século XX, assim como a própria construção do Código Mundial Antidoping que foi fruto de uma série de investimentos ao longo desse período.

Não se constitui como objetivo deste estudo debater as questões éticas no âmbito das definições destes critérios, pois importantes estudos já foram realizados sobre o tema (MIAH, 2006, 2008; RAMIREZ; RIBEIRO, 2005; TAVARES 2002, 2006). No entanto, cabe discutir as frágeis fronteiras dessas definições, na medida em que o uso de algumas tecnologias ou substâncias implica em diferentes formas de sujeição dos atletas.

No tocante aos incrementos utilizados para aumento do desempenho esportivo, Miah (2006) questiona o fato de nem todos os casos de aprimoramento esportivo serem contemplados no Código Mundial Antidoping. O autor alude, por exemplo, que no momento em que novos elementos, tecnologias ou equipamentos são postos em circulação na arena esportiva com vistas ao aumento de desempenho dos atletas, estes são levados para serem analisados, em primeira instância, pelas respectivas federações esportivas de cada modalidade, tendo o Código Mundial Antidoping como referência. No entanto, caso haja dúvida por parte da federação esportiva que analisa o caso, daí então o assunto é levado para discussão no âmbito da WADA-AMA. Portanto, nem todo processo de regulação do doping é simples ou fácil de ser resolvido, sendo que nem todo aprimoramento tecnológico está previsto ou está ao alcance das determinações da WADA-AMA.

Em outro estudo, Miah (2008, p. 28) argumenta que condenar determinadas aplicações tecnológicas antes mesmo de discutí-las no cenário acadêmico e científico internacional, analisando seus reais benefícios e malefícios aos atletas e ao esporte, rejeitando-as de antemão, "limita a maneira como as novas melhoras provenientes da tecnologia podem ser vistas". Desse modo, destaca o autor que há que se discutir com mais cautela e profundidade aquilo que será denominado como doping, especialmente na direção de uma diferenciação daquilo que é julgado como doping para aquilo que é apenas um melhoramento da performance humana no esporte. Assim, ao invés de taxar todo e qualquer melhoramento do desempenho humano, inicialmente e de antemão, como doping ou algo proibido, é preciso debater as bases em que tais restrições se assentam. Esta retórica da proibição é também referida por Rose (2013), quando o mesmo destaca as emergentes condições de vida que se apresentam à humanidade, considerando que em tal contexto, de aparente 'desordem' dos saberes e formas de vida até então experimentadas, "muitos estabeleceram comitês e comissões para tratar a aparentemente inevitável demanda que tais possibilidades parecem ter gerado - [reiterando] que uma "linha precisa ser desenhada' entre o permitido, o regulado e o proibido" (ROSE, 2013, p. 14).

É nesse sentido que Miah (2008) ressalta a necessidade de se questionar o uso do termo doping, a fim de distinguir o que deve ser considerado trapaça e o que deve ser considerado melhoramento no esporte. Aliás, existem inúmeras formas de melhoramento da performance esportiva que não são contemplados, tal como referido anteriormente, pelo Código Mundial Antidoping, e que não passam necessariamente pelo uso de "drogas para a modificação do desempenho, tal como a tecnologia esportiva ou avanços da engenharia" (MIAH, 2008, p. 31). Estas dificuldades de nomeação, definição e, consequentemente, regulação em torno das políticas antidoping no tocante às situações hodiernas de aprimoramento da performance humana geram problemas que, conforme Miah (2008), podem ser separados em dois escopos distintos: a) drogas e métodos atuais que ainda não foram suficientemente debatidos, regulados ou averiguados acerca da confiabilidade de detecção no âmbito científico e pela própria WADA-AMA; e b) práticas, métodos e substâncias do "futuro", para as quais já existem condições de permitirem sua ocorrência, mas que ainda não se tem notícia de sua efetiva aplicação. Ambas as situações incorrem em trazer dificuldades nas delimitações e regulações quanto ao doping. Um exemplo sobre tais dificuldades, no plano das substâncias e métodos já 
existentes e conhecidos, se refere ao uso de hormônios. Não apenas se tem registros das testagens antidoping nos usos dos hormônios da eritropoietina (EPO) e do crescimento (hGH), como se sabe que tais testagens não funcionam em cem por cento dos casos dos atletas que, porventura, as usem, embora já, há mais de dez anos, se tenha registros de seus usos crescentes nos atletas de alto rendimento (MIAH, 2008).

No caso das intituladas substâncias do "futuro", ou seja, aquelas substâncias, terapias ou métodos que se tem conhecimento da existência de condições tecnológicas para sua realização e produção, mas que ainda não se tem confirmação de sua utilização é possível citar, a partir dos estudos de Ramirez e Ribeiro (2005), os genes fortemente candidatos a serem desenvolvidos no âmbito do doping genético. Dentre os principais genes a serem desenvolvidos no escopo do melhoramento humano através de terapias genéticas, Ramirez e Ribeiro (2005) citam a eritropoietina (EPO), o fator de crescimento 1 (IGF-1), a miostatina (GDF-8), o fator de crescimento vascular (VEGF), a leptina (LEP) e o gene codificador de endorfina. Desse modo, as dificuldades quanto à regulação e controle dos usos desses métodos ou substâncias são diretamente proporcionais às possibilidades de detecção, reconhecimento e até mesmo classificação dos usos destas tecnologias no esporte. Além do mais, Dine (2003 apud RAMIREZ; RIBEIRO, 2005) destaca que a própria eritropoietina e os hormônios de crescimento, atualmente tomados enquanto medicamentos e produtos fabricados no campo da química e da bioquímica, já são produzidos pela engenharia genética há tempos, na medida em que se valem das técnicas e conhecimentos gênicos para sua fabricação, constituindo-se, assim, como um primeiro passo na direção do doping genético.

Além disso, existe uma série de outros métodos que não foram regulados pela WADAAMA, mas que são usados por atletas para aprimorarem sua performance esportiva, tornandoos otimizados. Um desses exemplos são as câmaras de altitude, ou hipobáricas, que procuram aumentar a capacidade de resistência da performance atlética simulando diferentes níveis de altitude e, portanto, de pressão atmosférica. Inicialmente, elas foram usadas para adaptação de atletas que disputam eventos esportivos em regiões com diferenças de altitude, porém, na atualidade, são usadas como forma de treinamento. Tal método não é considerado doping pela WADA-AMA, mesmo que de forma 'artificial' aumente a performance esportiva (MIAH, 2008). Outros exemplos que se inserem nesse escopo de discussão, a saber, as tecnologias contemporâneas que operam na direção de aumentar a performance e as formas de regulação pela WADA-AMA, incluem também outros métodos ou procedimentos. Miah (2006) destaca que os sistemas de tecnologias no esporte podem ser divididos segundo os modos pelos quais entendem a tecnologia: 1) as tecnologias que permitem o esporte acontecer (como, por exemplo, o motor e o carro, como na Fórmula 1);2) as tecnologias de segurança (capacetes de plástico e de fibra de vidro, no futebol americano, ou tênis apropriados para provas de corrida em meio à natureza); 3) tecnologias para melhoria de movimentos (como as roupas de natação, ciclismo ou pescaria esportiva); ou, ainda, 4) tecnologias de materiais que melhoram o desempenho (arcos de fibra de carbono, vara para salto em altura com fibras, etc.). Desse modo, existe um sem número de materiais e procedimentos que podem melhorar a performance para além daquilo que seria considerado o "natural" de um atleta. Miah $(2006,2008)$ argumenta que é necessário, antes de elaborar mecanismos regulatórios, abrir espaço para o debate acerca desses aprimoramentos humanos, pois o tipo de justificativa para o doping baseada "em conceitos como naturalidade, essência, etc., é precisamente o tipo de perspectiva que tem provado ser insuficiente para assegurar uma avaliação ética rigorosa dos modificadores de desempenho" (MIAH, 2008, p. 69, grifos do autor).

Uma das prerrogativas para que coloquemos tais questionamentos nas agendas de discussões acerca do doping no esporte se baseia no pressuposto de que a "genética e outras tecnologias emergentes apresentarão desafios [ainda] maiores (ou talvez insuperáveis) para a política de doping no esporte do que outras formas de modificação têm apresentado até agora" 
(MIAH, 2008, p. 69; RAMIREZ; RIBEIRO, 2005). Não obstante, na tentativa de compreender o incipiente doping genético à época, a WADA-AMA, junto com o instituto de pesquisa e educação Laboratório Cold Spring Harbor, no Banbury Centre, em Nova York, organizou um workshop sobre genética, com a presença de cerca de 40 experts dos campos de doping, medicina esportiva e genética, tendo como objetivo discutir a importância do potencial dano da tecnologia de terapia gênica para o aumento do aprimoramento da performance física (WADA-AMA, 2002a, p. 12). Uma das conclusões da conferência de Banbury foi de que o doping genético é tão antiético quanto qualquer outra forma de doping e que o uso da transferência genética para o aumento da performance parece ser um sintoma da geração atual de esportistas (WADA-AMA, 2002b, p. 19). Nesse ínterim, cabe destacar as discussões acerca do doping genético que giram em torno, por um lado, tanto dos danos e malefícios à saúde dos atletas que possam se submeter às terapias gênicas quanto, por outro, à própria ética do esporte e àquelas prerrogativas situadas no chamado 'espírito olímpico'. Portanto, há, aqui, duas grandes frentes acerca da proibição das tecnologias gênicas no aprimoramento das capacidades atléticas: as questões de saúde e as questões políticas envoltas numa determinada ética esportiva moderna. Ramirez e Ribeiro (2005) são contundentes ao afirmar que danos à saúde não são elementos constitutivos daquilo que é considerado doping, no entanto, servem de pressuposto para uma regulação dos métodos e substâncias consideradas doping. Ou seja: os danos à saúde são decorrências do uso do doping, mas não o constituem. Desse modo, sugerem os autores, os argumentos referentes à saúde como mecanismos reguladores do doping são frágeis, se comparados aos argumentos relativos aos princípios olímpicos, e concluem referindo que a carta olímpica, baseada em pressupostos éticos e morais do esporte é que deveria ser o guia de orientação das políticas do doping, e não os aspectos relacionados à saúde.

Entrementes, ainda sobre os resultados da referida conferência de Banbury, a WADAAMA comprometeu-se a desenvolver pesquisas que possam incluir a detecção das transferências genéticas e seus efeitos na arena esportiva, assim como, "uma linguagem proibitória do uso das tecnologias de transferência genética no aprimoramento da performance atlética a ser incluída no Código Mundial Antidoping" (WADA-AMA, 2002b, p. 19). No entanto, tal tarefa parecia (e ainda parece) ser distante de se alcançar, na medida em que se "reconhece a necessidade da continuidade de desenvolvimento e refinamento dos métodos que permitirão a detecção dos agravos e danos das tecnologias de transferência genética no esporte" (WADAAMA, 2002b, p. 19). Mesmo frente a estas dificuldades referentes às detecções e efeitos do doping genético, a WADA-AMA se posiciona de forma veemente contra seu uso, argumentando que os danos à saúde e a vida dos atletas podem ser altos, "pois se tem informações de alguns casos de câncer, como a leucemia, em pacientes que [em casos clínicos de terapia gênica] experimentaram a transferências de genes" (WADA-AMA, 2004, n. 3, p. 4).

Miah (2008), Dias (2011), Ramirez e Ribeiro (2005) e a própria WADA-AMA (2004, n. 3) apontam para o fato de não haver método de detecção confiável sobre as manipulações e terapias que podem acarretar o doping genético, sendo "largamente conhecido que a biópsia muscular pode ser o único meio de detectar algumas formas de manipulação genética no esporte, o que seria um desafio significativo para a política antidoping, dada a invasão de tal processo" (MIAH, 2008, p. 66). Assim, para haver testes de detecção de doping genético seria necessário consentimento por parte do atleta para a invasão em seu corpo e retirada de tecidos para averiguação posterior acerca do uso ou não das tecnologias gênicas. E mesmo assim, tal averiguação não possui grande confiabilidade, dado os mais diversos tipos de interferência que podem ocorrer nos corpos dos atletas e nas testagens.

Além do mais, o conhecimento genético pode favorecer o desempenho esportivo de diversas maneiras, seja por terapia gênica, transferência de genes, ingestão de substâncias geneticamente modificadas, manipulação de genes ou, ainda, uma forma de intervenção que não se caracterize diretamente como doping, mas faz uso desses saberes, como a seleção de 
atletas a partir do saberes e mapeamento genéticos. Não caberia aqui uma discussão aprofundada sobre os diferentes métodos de uso da engenharia genética no esporte, no entanto, cabe destacar que Munthe (2000 apud MIAH, 2008) agrupa os métodos antes aludidos em quatro categorias: criação de drogas geneticamente mais eficientes; modificação de células não hereditárias (tecido muscular, por exemplo); modificação de células hereditárias (por exemplo, células-tronco - antes mesmo do ser humano vir a nascer); e, por fim, a pré-seleção genética (escolha de atletas a partir de informações genéticas, como genótipo e biótipo compatível com determinada modalidade). De modo semelhante, Pilotto (2010) descreveu e analisou os tipos específicos de corpos de atletas concebidos para cada modalidade esportiva. No entanto, é importante frisar, as análises realizadas e os resultados produzidos no estudo de Pilotto (2010) indicam os tipos de corpos relacionados às modalidades esportivas específicas a partir de um "estilo de pensamento molar", para se valer do pensamento de Rose (2013), e não "molecular", que é aquele que parece operar no desdobramento do conhecimento genético na seleção de atletas aqui aludido.

Acerca desse último tópico, a saber, a seleção de atletas a partir dos saberes e técnicas genéticas, Goellner e Silva $(2007,2012)$ apontam para aquilo que eles denominam de emergência de uma nova forma de eugenismo, no qual a arena esportiva aparece como um lugar privilegiado para essas reflexões. Os autores exploram essa ideia a partir do argumento de que "se na eugenia a centralidade era ocupada pelos corpos hereditariamente bem-nascidos, na neoeugenia isso já não faz tanto sentido, sobretudo porque carrega o desejo de superação pela biotecnologia" (GOELLNER; SILVA, 2012, p. 197). E continuam os autores: "São justamente os investimentos nos corpos deficientes que se tornam elementos fundantes dessa neoeugenia" (Ibidem). Por deficientes, em nota, os autores se referem a todo e qualquer ser humano que não atingiu seu grau máximo de eficiência. Acrescentaria aqui, além desse argumento, que são humanos que não atingiram não apenas o máximo de sua eficiência, mas não atingiram a eficiência que gostariam de atingir, na medida em que a eficiência máxima não é mais determinada pela base 'natural', mas, sim, nas condições biotecnológicas hodiernas, por aquilo que o ser humano gostaria de ter/ser, tal como um cliente. Desse modo, haveria diferentes nuances entre uma nova eugenia e aquilo que Rose (2013) entende como cultura somática, em que os seres humanos e(m) seus corpos operam numa lógica de mercado, pautada por escolhas individuais nas alterações que gostariam de fazer sobre si mesmos.

Sobre os potenciais métodos de aprimoramento da performance humana através do conhecimento genético, foi somente em setembro de 2002 que a WADA-AMA incluiu, pela primeira vez, referências ao doping genético na lista de substâncias proibidas. Assim, a referência a este tipo de dopagem foi descrita e definida como "o uso não terapêutico de genes, elementos genéticos e/ou células que tem a capacidade de aprimorar a performance atlética" (WADA-AMA, 2002c, p. 9).

Ressalto novamente que o conhecimento genético e a engenharia genética possibilitam uma série de intervenções na otimização da performance esportiva que não apenas esses destacados pela WADA-AMA. Um exemplo da dificuldade de controle das aplicações desses saberes pode ser relatado a partir da descoberta do gene DREAM (downstream regulatory element antagonist modulator). Esse gene "sintetiza uma proteína que suprime a produção da dinorfina, produzida em resposta à dor ou ansiedade" (MIAH, 2008, p. 88). A possibilidade de sintetizar artificialmente esse gene não implica em aprimoramento ou aumento da performance, mas em diminuição da dor ou ansiedade. Entrementes, essa aplicação não opera na lógica "do mais" (o que normalmente é usado como critério para a construção de argumentos contrários ao uso de técnicas gênicas), mas opera na lógica "do menos", na medida em que diminui a dor. Aqui, não há um incremento do rendimento, mas a diminuição de um possível entrave ao rendimento. Se retomarmos o excerto anterior da WADA-AMA acerca do uso das tecnologias genéticas, no qual afirma a proibição do uso das técnicas e saberes genéticos que 
possuem "a capacidade de aprimorar a performance atlética" (WADA-AMA, 2002c, p. 9), perceberemos que o uso do gene DREAM parece não incorrer nessas proibições. Além do mais, não caberia a esse gene entrar no escopo proibitivo porque uma série de outros fármacos, inclusive comercializados normalmente em farmácias e até mesmo em supermercados, também possuem a capacidade de eliminar e/ou diminuir a dor. A única diferença entre esses fármacos tradicionais e o gene DREAM é a tecnologia envolvida em suas fabricações. No entanto, tais critérios de inclusão e/ou exclusão não são abordados pela WADA-AMA.

$\mathrm{Na}$ já referida conferência sobre doping genético, promovida pela WADA-AMA no Banbury Centre, em Nova York, no ano de 2002, uma das conclusões gerais foi a necessidade de distinção entre terapia gênica e aprimoramento gênico, através de discussões públicas sobre o tema e da necessidade de desenvolvimento de modelos sociais e de políticas de regulação, antes que venham a ocorrer abusos vinculados ao uso não autorizado destes mecanismos, e não apenas depois que ocorrerem, pois podem resultar em 'efeitos colaterais' indesejáveis.

Existem exemplos abundantes sobre os 'efeitos colaterais' negativos das terapias gênicas aplicadas em casos clínicos, advindos de algumas das ocasiões em que se autorizou a realização de tais experimentações, assim como também há casos bem sucedidos (FAGOTLARGEAULT, 2004; RAMIREZ; RIBEIRO, 2005; WADA-AMA, 2004, n. 3). Murray, expert em bioética, em entrevista à revista Play True (WADA-AMA, 2004, n. 3) ressalta casos em que a terapia gênica foi aplicada em onze crianças com vistas à melhora de uma patologia (imunodeficiência grave combinada ligada ao X, ou, X-SCID), mas que, ao longo do tempo, levou a maioria delas a desenvolver leucemia. Fagot-Largeault (2004), por sua vez, destaca casos em que a tecnologia gênica foi aplicada na reprodução assistida, havendo também efeitos colaterais. Por fim, Ramirez e Ribeiro $(2005$, p. 11) relatam a "morte de um adolescente que participava de um protocolo para Deficiência da Ornitina Transcarboxilase, em 1999", resultante de uma resposta imunológica do organismo ao vetor injetado no corpo do adolescente. Mesmo diante destes casos negativos de terapia gênica, é possível também indicar situações em que este tipo de terapia ocorreu positivamente, como no mesmo caso citado por Murray (WADA-AMA, 2004, n. 3), em que nem todas as crianças submetidas à terapia genética desenvolveram leucemia, sendo que algumas tiveram êxito no procedimento. Desse modo, é possível inferir que "a reposição de um gene defeituoso ou ausente, ou o bloqueio gênico da síntese de uma proteína em uma pessoa submetida à terapia gênica oferece tantos benefícios que eventuais efeitos colaterais" podem ser considerados insignificantes (RAMIREZ; RIBEIRO, 2005 p. 13).

Tais discussões reiteram o caráter conflitivo do uso das terapias genéticas tanto na sociedade de modo geral como no esporte especificamente, sendo ainda bastante incipiente a tentativa de seus usos na modificação das características esportivas para o aumento do desempenho em atletas de alto rendimento. No entanto, mesmo ainda incipientes, eles povoam o pensamento social e científico relativo ao esporte, e são alvo de uma série de investimentos que buscam conhecer, classificar e caracterizar seus possíveis usos e aplicações.

O doping genético é compreendido, portanto, como qualquer outro tipo de doping convencional, e, desse modo, é proibido, mesmo que ainda não se tenha vasto conhecimento acerca de sua aplicação e detecção. Entrementes, mesmo sendo considerada uma forma de dopagem como qualquer outra, sabe-se que a tecnologia envolvida em sua aplicação é da ordem das mais altas especialidades científicas, na medida em que a terapia gênica aplicada ao esporte, no aumento das potencialidades esportivas, "é um procedimento altamente experimental realizado por pouquíssimos centros clínicos e de investigação no mundo" (WADAAMA, 2004, n. 3), o que lhe confere um caráter completamente diferenciado das outras formas de incremento do desempenho de atletas.

\section{Uma necessária agenda de discussão}


É possível considerar que há diferentes gradientes e limiares acerca do aumento do desempenho esportivo, assim como, distintas maneiras pelas quais tais incrementos podem ser considerados doping pela WADA-AMA. Por um lado, existe o argumento de que é considerado doping aquilo que é listado como proibido no Código Mundial Antidoping e nas listas de substâncias proibidas, o que confere a esse posicionamento um caráter heurístico. Por outro lado, quando explorados os diferentes argumentos e, principalmente, situações relacionadas ao doping esportivo, percebe-se o quão difícil é determinar os critérios de proibição. Diferentes tecnologias utilizadas no aumento do desempenho humano no esporte são analisadas de formas distintas em referência ao doping, como, por exemplo, suplementos alimentares, ingestão de anabolizantes, uso de psicotrópicos, agentes mascaradores, terapia genética e outros. O que está em pauta, aqui, é a difícil definição dos critérios sobre doping, em que alguns procedimentos ou substâncias passam a compor o rol de elementos proibidos mesmo que tenham uma influência menor - ou mesmo nenhuma - no desempenho esportivo, sendo arbitrariamente classificados a partir de argumentos como saúde, moral, equidade, justiça, etc. Tais discussões ressaltam o caráter conflitivo e contraditório acerca das definições sobre o doping.

Entretanto, dentre as distintas tecnologias envolvidas na melhoria da performance esportiva, algumas atuam diretamente na configuração de novas subjetividades vinculadas às biotecnologias. É, então, na esteira das emergentes tecnologias sobre a vida que novos tipos de atletas podem ser fabricados: são aqueles sujeitos esportivos que se valem das mais diversas possibilidades presentes na atualidade para operar transformações em seus corpos e capacidades atlético-desportivas.

Essas novas capacidades de transformação de si e do desempenho humano acabam por borrar as fronteiras e definições tradicionais acerca do doping e das capacidades humanas, causando confusões e limitações de toda ordem para os órgãos responsáveis pelo gerenciamento da vitalidade e performance esportiva. Há que se colocar na agenda de discussão do esporte de alto rendimento e do doping tais entrelaçamentos contemporâneos, a fim de que possamos andar a par e passo com as tecnologias emergentes e suas influências nos atletas e esportes de alto rendimento.

\title{
GRADIENTS OF DOPING AND DEFINITIONS OF BORDERS: CHALLENGES AND CONTINGENCIES IN HIGH PERFORMANCE SPORT
}

\begin{abstract}
Given the contemporary conditions of change in human capabilities in the sports field, this text aims to discuss the limits and contingencies involved in the definition and regulation of doping in elite sport. Articulating discussions about the optimization of physical and sports performance and records from the World Anti-Doping Agency, we established a discussion of doping thresholds and the difficulties posed by such conditions in the conduct of its regulatory processes. It is considered that there is a need for a broad and revisional debate of contemporary doping policies, as well as continued attention to the transformation processes of human capacities with regard to elite sport.
\end{abstract}

Keywords: Sports. Doping in sports. Athletic performance. Performance-Enhancing Substances.

\section{GRADIENTES DE DOPAJE Y DEFINICIONES DE LAS FRONTERAS: RETOS Y CONTINGENCIAS EN EL DEPORTE DE ALTO RENDIMIENTO}

\section{Resumen}


Teniendo en cuenta las condiciones contemporáneas de alteración de las capacidades humanas en el campo deportivo, este trabajo tiene como objetivo discutir los límites y las contingencias que forman parte de la definición y regulación del dopaje en el deporte de alto rendimiento. Articulando discusiones acerca de las posibilidades de optimización del rendimiento físicodeportivo y los registros de la Agencia Mundial Antidopaje, se establece una discusión sobre los umbrales del dopaje y de las dificultades planteadas por esas condiciones en la conducción de sus procesos de regulación. Se considera la necesidad de un debate amplio y revisional de las políticas contemporáneas de dopaje, así como la atención continuada a los procesos de transformación de las capacidades humanas en relación con el deporte de alto rendimiento.

Palabras clave: Deportes. Dopaje en el deporte. Rendimiento atlético. Sustancias para mejorar el rendimiento.

\section{Referências}

COUTO, E. S. O zumbido híbrido. A filosofia ciborgue do corpo. In: Revista Margem, São Paulo, n. 13, p. 85-99, jun. 2001.

DIAS, R. G. Genética, Performance Física Humana e Doping Genético: o Senso Comum Versus a Realidade Científica. In: Revista Brasileira de Medicina do Esporte, v. 17, n. 1, p. 62 70, jan./fev. 2011.

FAGOT-LARGEAULT, A. A introdução na medicina de técnicas oriundas da genética ocasionou uma ruptura antropológica? In: Scientiæstudia, São Paulo, v. 2, n. 2, p. 161-177, 2004.

FEDER, M. et al. Informações sobre o uso de medicamentos no esporte. In: Revista Brasileira Medicina do Esporte, São Paulo, v. 6, n. 4, p. 125-130, jul./ago. 2000.

FOUCAULT, M. Crise da medicina ou crise da antimedicina. Verve, São Paulo, v. 18, p. 167-194, 2010.

GAUDENZI, P.; ORTEGA, F. O estatuto da medicalização e as interpretações de Ivan Illich e Michel Foucault como ferramentas conceituais para o estudo da desmedicalização. Interface, Botucatu, v. 16, n. 40, p. 21-34, jan./mar. 2012.

GOELLNER, S. V.; SILVA, A. L. S. Universo biotecnológico e fronteiras partidas: esporte, gênero e novo eugenismo. In: Gênero, Niterói, Rio de Janeiro, v. 7, n. 2, p. 79-89, 2007.

Biotecnologia e neoeugenia - olhares a partir do esporte e da cultura fitness. In: COUTO, E.; GOELLNER, S. V. (Org.). O triunfo do corpo: polêmicas contemporâneas. Petrópolis, RJ: Vozes, 2012. p. 198-215.

MIAH, A. Rethinking enhancement in sport. In: Annals of the New York Academy of Sciences, New York, n. 1093, p. 301-320, 2006.

Atletas geneticamente modificados: ética biomédica, doping genético e esporte. São Paulo: Phorte, 2008. 
PILOTTO, F. M. Educação corporal de atletas na ginástica artística. 2010. 228 f?. Tese (Programa de Pós-graduação em Educação) - Faculdade de Educação, Universidade Federal do Rio Grande do Sul, Porto Alegre, 2010.

POLI NETO, P.; CAPONI, S. N. C. A medicalização da beleza. In: Revista Interface - Comunicação, Saúde e Educação, Botucatu, São Paulo, n. 23, v. 11, p. 569-84, set./dez. 2007.

RAMIREZ, A.; RIBEIRO, Á. Doping genético e esporte. In: Revista Metropolitana de Ciências do Movimento Humano, São Paulo, v. 5, n. 2, p. 9-20, jun. 2005.

RIBEIRO, R. J. Novas fronteiras entre natureza e cultura. In: NOVAES, A. (Org.). O homem-máquina: a ciência manipula o corpo. São Paulo: Companhia das Letras, 2003. p. $15-36$.

ROSE, N. A política da própria vida: biomedicina, poder e subjetividade no Século XXI. São Paulo: Paulus, 2013.

SANDOVAL, A. E. Medicina do Esporte: princípios e prática. Porto Alegre: Artmed, 2005.

TAVARES, O. Doping: argumentos em discussão. In: Revista Movimento, Porto Alegre, n. 1, p. 41-55, jan./abr., 2002.

Notas Para Uma Análise da Produção em Ciências Sociais Sobre Doping no Esporte. In: Esporte e Sociedade, Rio de Janeiro, n. 2, mar./jun. 2006. Disponível em: <http://www.lazer.eefd.ufrj.br/espsoc>. Acesso em: 30 set. 2015.

WORLD ANTI-DOPING AGENCY - AGÊNCIA MUNDIAL ANTIDOPING (WADAAMA). WADANEWS, n. 1, fev. 2002a. Disponível em: <http://www.wada-ama.org/>. Acesso em: 02 jul. 2015.

WORLD ANTI-DOPING AGENCY - AGENCIA MUNDIAL ANTIDOPING (WADAAMA). WADANEWS, n. 2, jun. 2002b. Disponível em: <http://www.wada-ama.org/>. Acesso em: 02 jul. 2015.

WORLD ANTI-DOPING AGENCY - AGÊNCIA MUNDIAL ANTIDOPING (WADAAMA). WADANEWS, n. 3, dez. 2002c. Disponível em: <http://www.wada-ama.org/>. Acesso em: 02 jul. 2015.

WORLD ANTI-DOPING AGENCY - AGÊNCIA MUNDIAL ANTIDOPING (WADAAMA). PLAY TRUE, n. 3, 2004. Disponível em: <http://www.wada-ama.org/>. Acesso em: 02 jul. 2015.

WORLD ANTI-DOPING AGENCY - AGÊNCIA MUNDIAL ANTIDOPING (WADAAMA). PLAY TRUE, n. 2, 2009. Disponível em: <http://www.wada-ama.org/>. Acesso em: 02 jul. 2015. 
Endereço para correspondência:

gsmanske@yahoo.com.br

George Saliba Manske

Universidade do Vale do Itajaí

R. Uruguai, 458

Centro, Itajaí - SC, 88302-202 